\section{WHAT IS HEPATITIS?}

- 'Hepatitis' means inflammation or swelling of the liver. It can be caused by chemicals or drugs, or by different kinds of viral infections.

- Infection with one type of hepatitis virus does NOT give protection against infection with other hepatitis viruses.

One common cause of hepatitis is the hepatitis A virus.

\section{WHAT IS HEPATITIS A?}

- Hepatitis A is a viral infection of the liver which is associated with the symptoms of feeling unwell, aches and pains, fever, nausea, lack of appetite, abdominal discomfort and darkening of the urine, which is followed within a few days by jaundice (yellowing of the eyeballs and skin).

- Illness usually lasts approximately 1-3 weeks (although some symptoms can last several months) and is almost always followed by complete recovery. Small children who become infected usually have no symptoms.

- Hepatitis A does NOT cause long-term liver disease and deaths caused by hepatitis $\mathrm{A}$ are rare.

- The period between contact with the virus to the development of symptoms is usually four weeks, but can range from two to seven weeks.

- Infected people can pass on the virus to others from two weeks before the development of symptoms until one week after the appearance of jaundice (about three weeks in total).

- Very large amounts of the virus are found in faeces (stools) of an infectious person during the infectious period.

- The virus can survive in the environment for several weeks in the right conditions (for example, in sewage).

\section{HOW IS HEPATITIS A TRANSMITTED?}

Hepatitis A is usually transmitted when virus from an infected person is swallowed by another person through:

- eating food that has been handled by an infectious person;

- touching nappies, linen and towels soiled with the faeces of an infectious person;

- direct contact (including sexual) with an infectious person.

\section{REPORTED OUTBREAKS OF HEPATITIS A HAVE BEENTRACEDTO:}

- person-to-person spread, including among men who have sex with men;

- drinking water contaminated with sewage;

- eating food (contaminated with sewage) such as shellfish;

- eating food contaminated by infectious food handlers.

Hepatitis A continues to be a problem for people travelling overseas, especially people visiting developing countries where hepatitis A is common.

\section{WHO CAN GET HEPATITIS?}

Those who have not had hepatitis A and who have not been vaccinated against it may be at risk of catching the disease.

\section{WHAT CAN BE DONE TO AVOID INFECTING OTHERS?}

- Everyone should wash their hands thoroughly with soap and running water, after going to the toilet and before preparing food and drinks.

If you have hepatitis A, you should avoid the following activities while infectious (that is, until at least one week after onset of jaundice):

- do NOT prepare food or drink for other people

- do NOT share eating or drinking utensils with other people

- do NOT share linen and towels with other people

- abstain from sex

- wash eating utensils in soapy water, and machine wash linen and towels.

\section{WHAT CAN BE DONETO AVOID CATCHING HEPATITIS A?}

Always wash your hands thoroughly in soap and running water:

- before eating

- after going to the toilet

- after handling objects such as nappies and condoms.

Avoid sharing food, drinks, cigarettes and other smoking implements with other people. 


\section{ISTHERE ANYTREATMENT FOR HEPATITIS A?}

There is no specific treatment for hepatitis A. Household contacts and sexual partners of an infectious person usually need an injection of immunoglobulin. The injection may prevent or reduce illness if given within two weeks of contact with the infectious person.

\section{VACCINATION}

A safe and effective vaccine is available against hepatitis A. The vaccine may take up to two weeks to provide protection. Vaccination is recommended for the following groups of people:

- travellers to countries (most developing countries) where hepatitis A is common

- frequent visitors to rural and remote indigenous communities

- men who have sex with men

- child day-care and pre-school personnel

- the intellectually disabled and their carers

- some health care workers who work in or with indigenous communities

- sewerage workers
- plumbers

- injecting drug users

- patients with chronic liver disease

- people with haemophilia who may receive pooled plasma concentrates.

\section{SHOULD PEOPLE WHO HAVE HEPATITIS A BE EXCLUDED FROM WORK AND SCHOOL?}

- People who handle food or drink must be excluded from work for at least one week after the onset of jaundice (that is, while infectious).

- People whose work involves close personal contact, such as child carers and health workers, should not work while they are infectious.

- Staff of childcare facilities should not attend while infectious.

- Children and adolescents should not attend childcare facilities or school while infectious.

- All patients should check with their doctor before returning to work or school.

For more information please contact your local public health unit, community health centre, or doctor.

\section{NSW PUBLIC HEALTH BULLETIN}

The NSW Public Health Bulletin is a publication of the NSW Department of Health. The editor is Dr Lynne Madden, Manager, Public Health Training and Development Unit. The assistant editor is Ms Allison Salmon. Dr Michael Giffin is managing editor.

The Bulletin aims to provide its readers with population health data and information to support effective public health action.

\section{Submission of articles}

Articles, news and comments should be 1000 words or less in length and include a summary of the key points to be made in the first paragraph. References should be set out in the Vancouver style, described in the New England Journal of Medicine, 1997; 336: 309-315. Send submitted articles on paper and in electronic form, either on disc (Word for Windows is preferred), or by email. The article must be accompanied by a letter signed by all authors. Full instructions for authors are available on request from the editor.

\section{Editorial correspondence}

Please address all correspondence and potential contributions to The Editor, NSW Public Health Bulletin, Locked Mail Bag 961, North Sydney NSW 2059 or to Lmadd@doh.health.nsw.gov.au. Tel (02) 9391 9956, Fax (02) 93919232.

\section{Distribution}

Please contact your local Public Health Unit or telephone (02) 93919942 to obtain copies of the NSW Public Health Bulletin or to notify us of a change of address. The Bulletin can be accessed via the Internet from the Department's Web site at: www.health.nsw.gov.au/public-health/phb/phb.html.

Back issues can be obtained from the Public Health Training and Development Unit, Locked Mail Bag 961, North Sydney NSW 2059. 